\title{
Qualidade da produção da bananeira Nanicão em função do uso de biofertilizantes
}

\author{
José G. R. dos Santos ${ }^{1}$, Raimundo Andrade ${ }^{2}$, Pablícia O. Galdino ${ }^{3}$, \\ Ayonna S. F. Linhares ${ }^{4}$, Paloma M. E. Maia ${ }^{5} \&$ Antonio S. de Lima ${ }^{6}$ \\ ${ }^{1}$ CCHA/UEPB. Catolé do Rocha, PB. E- mail: josegeraldo@uepb.edu.br (Autor correspondente) \\ ${ }^{2}$ CCHA/UEPB. Catolé do Rocha, PB. E- mail: raimundoandrade@uepb.edu.br \\ ${ }^{3}$ UEPB. Campina Grande, PB. E- mail: pabliciaog@hotmail.com \\ ${ }^{4}$ CCHA/UEPB. Catolé do Rocha, PB. E- mail: savanak9@hotmail.com \\ ${ }^{5}$ CCHA/UEPB. Catolé do Rocha, PB. E- mail: pmemaia@hotmail.com \\ ${ }^{6}$ UAEA/UFCG. Campina Grande, PB. E- mail: antoniolima_agro@hotmail.com
}

\section{Palavras-chave:}

Musa spp.

adubação orgânica

soro

\begin{abstract}
R E S U M O
Com esta pesquisa objetivou-se estudar os efeitos de 5 doses de 4 diferentes tipos de biofertilizante na produção da bananeira Nanicão, em 3 ciclos sucessivos. O experimento foi conduzido em condições de campo, na Escola Agrotécnica do Cajueiro, no município de Catolé do Rocha, estado da Paraíba, Brasil. O solo da área é classificado como Neossolo Flúvico, com textura franco arenosa. O experimento foi conduzido entre os meses de junho de 2008 a junho de 2011. O delineamento experimental adotado foi o de blocos casualizados com 20 tratamentos no esquema fatorial $5 \times 4$ (doses $\mathrm{x}$ tipos) de biofertilizantes, com quatro repetições. Os resultados mostram que os tipos de biofertilizante não afetaram as variáveis de qualidade da produção; o comprimento e o diâmetro do fruto aumentaram com o incremento da dose de biofertilizante até limites ótimos; o comprimento do fruto das plantas do segundo ciclo foi superior ao das plantas dos primeiro e terceiro ciclos; o diâmetro do fruto das plantas do segundo ciclo foi superior ao das plantas dos primeiro e terceiro ciclos e os valores de ${ }^{\circ} \mathrm{Brix}$ e de $\mathrm{pH}$ da polpa do fruto não foram afetados pelas doses de biofertilizante aplicadas.
\end{abstract}

Key words:

Musa spp.

organic fertilization

serum

\section{Quality of production of banana Nanicão under different biofertilizers}

\begin{abstract}
A B S T R A C T
The objective of this research was to study the effects of 5 doses of 4 different types of biofertilizer in production of banana Nanicão in 3 successive cycles. The experiment was conducted under field conditions at Escola Agrotécnica of the Cajueiro in the municipality of Catolé do Rocha, in the state of Paraíba, Brazil. The soil in the area is classified as Entisol with sandy loam texture. The experiment was conducted during June 2008 to June 2011. The experimental design was a randomized block design with 20 treatments in a $5 \times 4$ factorial scheme (doses $\mathrm{x}$ types) of biofertilizers with four replications. The results show that the types of biofertilizers did not affect the production quality, the length and diameter of fruit increased with increasing dose of biofertilizer to optimum limits, the length of the fruit of the second cycle was more than that of plants of first and third cycles, the diameter of the fruit of the second cycle of the crop was higher than the first and third cycles and values of ${ }^{\circ} \mathrm{Brix}$ and $\mathrm{pH}$ of the pulp of the fruit were not affected by biofertilizer doses.
\end{abstract}

\section{INTRODUÇÃo}

A banana (Musa spp.) é uma das frutas mais consumidas no mundo na forma fresca cultivada na maioria dos países tropicais e de Norte a Sul do Brasil, garantindo emprego e renda para milhares de brasileiros (Oliveira \& Souza, 2003). A cultura da banana assume importância econômica e social em todo o mundo sendo cultivada em mais de 80 países tropicais, principalmente por pequenos agricultores (Gonçalves et al., 2008).

O Brasil é o terceiro maior produtor mundial de bananas com produção aproximada de 7,2 milhões de toneladas, em uma área em torno de 520 mil hectares destacando-se o estado da Bahia como maior produtor nacional da fruta (Agrianual, 2009). Na fruticultura brasileira a banana ocupa o segundo lugar em volume de frutas produzidas e a terceira posição em área colhida situando-se a segunda fruta como a mais consumida do país, depois da laranja (Agrianual, 2009). O mercado interno consome praticamente toda a produção nacional com um consumo per capita de 29,0 $\mathrm{kg}$ ano ${ }^{-1}$ (Gonçalves et al., 2008).

No Brasil, o advento da agricultura orgânica foi iniciado na década de 90, sendo os biofertilizantes líquidos empregados no controle de pragas e doenças, no crescimento, desenvolvimento 
e nutrição das plantas (Tracth \& Bettiol, 1997), preparados na propriedade rural utilizando-se esterco fresco de animais, restos de cultura, leguminosas, resíduos orgânicos e outros ingredientes específicos, através dos processos de fermentação aeróbia e anaeróbia (Santos \& Santos, 2008).

No solo, os adubos orgânicos melhoram as características físicas, químicas e biológicas, além de proporcionar, às plantas, maior tolerância ao ataque de pragas e doenças quando aplicados na forma líquida via foliar (Damatto Júnior et al., 2006; 2009) e de funcionar como estimulante fito-hormonal, resultando em plantas mais equilibradas (Santos \& Akiba, 1996).

$\mathrm{O}$ aumento do $\mathrm{pH}$ do solo devido à adição de resíduos orgânicos tem sido atribuído à própria adsorção de hidrogênio e alumínio na superfície do material orgânico (Wong et al., 1995). Dentre os princípios básicos do cultivo orgânico se inclui a proteção do solo, do homem e do meio ambiente, favorecendo o desenvolvimento rural e contribuindo para melhores condições de vida (Sarudi et al., 2003).

A exploração orgânica de fruteiras tropicais com ênfase para a bananeira é de fundamental importância na programação de uma alimentação equilibrada e, consequentemente, para a saúde humana (Guerra et al., 2007). Borges et al. (2002) observaram efeitos positivos da adubação orgânica em bananeiras em que o uso de esterco como fonte de adubo promoveu aumento do número e comprimento de frutos por cacho.

Objetivou-se com este trabalho avaliar a qualidade da produção da bananeira Nanicão em ciclos sucessivos, submetida a doses de diferentes tipos de biofertilizante.

\section{Material e Métodos}

O experimento foi conduzido no período de agosto de 2007 a janeiro de 2010, em condições de campo, na Escola Agrotécnica do Cajueiro, no Centro de Ciências Humanas e Agrárias - CCHA, Campus IV da UEPB, distando $2 \mathrm{~km}$ da sede do município de Catolé do Rocha-PB, situado na região semiárida localizada pelas coordenadas geográficas: $6^{\circ} 21^{\prime}$ de latitude sul e $37^{\circ} 45^{\prime}$ de longitude ao oeste do meridiano de Greenwich, com altitude de $250 \mathrm{~m}$.

O clima do município, de acordo com a classificação de Koppen, é do tipo BSWh', ou seja, quente e seco do tipo estepe, com temperatura média mensal superior a $18^{\circ} \mathrm{C}$, durante todo $o$ ano.

O delineamento experimental adotado foi o de blocos casualizados com 20 tratamentos no esquema fatorial $5 \times 4$ (doses $\mathrm{x}$ tipos) de biofertilizantes, com quatro repetições (1 planta por parcela). Foram estudados os efeitos de 4 tipos $\left(B_{1}\right.$ não enriquecidos à base de esterco, $\mathrm{B}_{2}$ - enriquecidos à base de esterco, $\mathrm{B}_{3}$ - não enriquecidos à base de soro e $\mathrm{B}_{4}$ - enriquecidos à base de soro) e de 5 doses de biofertilizante $\left(\mathrm{D}_{1}=0, \mathrm{D}_{2}=0,4\right.$, $\mathrm{D}_{3}=0,8, \mathrm{D}_{4}=1,2$ e $\mathrm{D}_{5}=1,6 \mathrm{~L}$ por planta por vez) na qualidade da produção da bananeira Nanicão em três ciclos sucessivos.

O solo da área experimental é classificado como Neossolo Flúvico, com textura franco arenosa composta de $639 \mathrm{~g} \mathrm{~kg}^{-1} \mathrm{de}$ areia, $206 \mathrm{~g} \mathrm{~kg}^{-1}$ de silte e $154 \mathrm{~g} \mathrm{~kg}^{-1}$ de argila, com densidade aparente de $1,41 \mathrm{~kg} \mathrm{dm}^{-3}$, umidade de saturação de $231,6 \mathrm{~g} \mathrm{~kg}^{-1}$, umidade de capacidade de campo de 112,3 $\mathrm{g} \mathrm{kg}^{-1}$ e umidade de ponto de murcha permanente de $65,6 \mathrm{~g} \mathrm{~kg}^{-1}$, apresentando $\mathrm{pH}$ de 7,21, CEes de $0,62 \mathrm{dS} \mathrm{m}^{-1}$ e CTC de $8,39 \mathrm{cmol}_{\mathrm{c}} \mathrm{kg}^{-1}$, além de $1,24 \%$ de matéria orgânica. A água utilizada na irrigação apresenta $\mathrm{pH}$ de 7,53 , condutividade elétrica de $0,8 \mathrm{dS} \mathrm{m}^{-1} \mathrm{e}$ RAS de $2,88\left(\mathrm{mmol} \mathrm{L}^{-1}\right)^{1 / 2}$.

O preparo do solo para o plantio das mudas ( $1^{\circ}$ ciclo) constou de uma aração na profundidade de $30 \mathrm{~cm}$ e 2 gradagens cruzadas. Foram utilizadas mudas de bananeira Nanicão, tipo "chifre", plantadas no espaçamento de 2,5 x 2,0 m, em covas com dimensões de 50 × 50 × $50 \mathrm{~cm}$, com uma densidade da ordem de 2.000 plantas ha $\mathrm{A}^{-1}$. Por ocasião do plantio os pseudocaules das mudas foram cortados em forma de bisel, ficando com tamanho médio de $30 \mathrm{~cm}$.

As mudas foram tratadas com uma solução à base de cloro visando eliminar possíveis infestações do moleque da bananeira (Cosmopolitus sordidus, Germar), colocando-se $5 \mathrm{~L}$ do produto em $1000 \mathrm{~L}$ de água e se fazendo, em seguida, imersão das mudas durante $24 \mathrm{~h}$.

A adubação de fundação da bananeira foi feita com esterco bovino curtido colocando-se $3,5 \mathrm{~kg}$ por cova, equivalente a $30 \mathrm{~g}$ de $\mathrm{P}_{2} \mathrm{O}_{5}$ por cova ou $40 \mathrm{~kg} \mathrm{ha}^{-1}$, conforme recomendação da análise de solo. As adubações de cobertura foram realizadas mensalmente sendo utilizados os tipos e as dosagens de biofertilizantes preconizados.

Os biofertilizantes cujas composições podem ser observadas na Tabela 1 foram produzidos de forma anaeróbia, em biodigestores formados por recipientes plásticos com tampa roscada, com capacidade individual para $240 \mathrm{~L}$, contendo uma mangueira ligada a uma garrafa plástica transparente com água para retirada do gás metano produzido pela fermentação do material pelas bactérias.

O biofertilizante do tipo $\mathrm{B}_{1}$ foi produzido à base de esterco verde de vacas em lactação (70 kg) e água (120 L) adicionandose $5 \mathrm{~kg}$ de açúcar e $5 \mathrm{~L}$ de leite para acelerar o metabolismo das bactérias. Para a produção do biofertilizante $\mathrm{B}_{2}$, foram utilizados $70 \mathrm{~kg}$ de esterco verde de vacas em lactação, $120 \mathrm{~L}$ de água, $3 \mathrm{~kg}$ de farinha de rocha, $3 \mathrm{~kg}$ de cinzas de madeira, $5 \mathrm{~kg}$ de açúcar e $5 \mathrm{~L}$ de leite. $\mathrm{O}$ biofertilizante $\mathrm{B}_{3}$ foi produzido à base de $90 \mathrm{~L}$ de soro (obtido no processo de produção de queijo) e $5 \mathrm{~kg}$ de açúcar. O biofertilizante $\mathrm{B}_{4}$ foi produzido à base de $90 \mathrm{~L}$ de soro, $3 \mathrm{~kg}$ de farinha de rocha, $3 \mathrm{~kg}$ de cinzas de madeira e $5 \mathrm{~kg}$ de

Tabela 1. Características químicas dos biofertilizantes utilizados na pesquisa*

\begin{tabular}{|c|c|c|c|c|}
\hline \multirow{2}{*}{$\begin{array}{l}\text { Características } \\
\text { químicas }\end{array}$} & \multicolumn{4}{|c|}{ Tipos de Biofertilizante } \\
\hline & $B_{1}$ & $\mathbf{B}_{2}$ & $\mathbf{B}_{3}$ & $\mathbf{B}_{4}$ \\
\hline $\mathrm{pH}$ & 6,83 & 6,34 & 6,52 & 7,10 \\
\hline $\mathrm{CE}-\mathrm{dS} \mathrm{m}^{-1}$ & 7,55 & 8,08 & 4,41 & 5,13 \\
\hline Nitrogênio $\left(\mathrm{g} \mathrm{kg}^{-1}\right)$ & 1,30 & 1,00 & 0,50 & 0,60 \\
\hline Fósforo $\left(\mathrm{mg} \mathrm{dm}^{-3}\right)$ & 310,20 & 317,60 & 65,40 & 74,90 \\
\hline Enxofre $\left(\mathrm{mg} \mathrm{dm}^{-3}\right)$ & 14,45 & 15,49 & 3,19 & 3,65 \\
\hline Sódio $\left(\mathrm{cmol}_{\mathrm{c}} \mathrm{dm}^{-3}\right)$ & 3,05 & 3,27 & 1,24 & 1,34 \\
\hline Potássio $\left(\mathrm{cmol}_{\mathrm{c}} \mathrm{dm}^{-3}\right)$ & 1,57 & 1,68 & 0,84 & 0,91 \\
\hline Cálcio $\left(\mathrm{cmol}_{\mathrm{c}} \mathrm{dm}^{-3}\right)$ & 3,46 & 3,71 & 1,53 & 1,75 \\
\hline Magnésio $\left(\mathrm{cmol}_{\mathrm{c}} \mathrm{dm}^{-3}\right)$ & 2,24 & 2,40 & 0,94 & 1,20 \\
\hline
\end{tabular}

* Análise feita no Laboratório de Análise de Tecido de Planta, Centro de Ciências Agrárias da UFPB, Campus II, Areia, PB 
açúcar. A fermentação das bactérias durava aproximadamente 35 dias sendo o material coado em uma peneira para separar a parte líquida da sólida.

$\mathrm{Na}$ condução da pesquisa em campo foram realizadas capinas manuais na proximidade do colo da planta ou touceira para manter a cultura isenta de ervas daninhas não havendo competição por água e nutrientes. Foram feitos, sistematicamente, desbaste de filhotes e limpeza de folhas caducas e eliminação de corações ou mangarás após a formação do cacho.

A bananeira foi irrigada através de uma adaptação do sistema de irrigação localizado denominado "Bubbler", desenvolvido pela Universidade do Arizona (USA), sendo a condução da água feita através de canos e mangueiras utilizando-se a ação da gravidade. A água utilizada no experimento foi proveniente de um poço amazonas localizado próximo à área experimental, tendo sido bombeada para duas caixas d'água acopladas, elevadas a $3 \mathrm{~m}$ de altura, para fornecer pressão hidráulica suficiente.

A água foi deslocada através de canos de PVC de $50 \mathrm{~mm}$ e de mangueiras de $1 / 2$ polegada, espaçadas $2,5 \mathrm{~m}$, além de mangueiras de $6 \mathrm{~mm}$ para a saída da água. Em cada planta foi construída uma minibacia circular com raio de $0,7 \mathrm{~m}$ aumentado para $1,0 \mathrm{~m}$ a partir do oitavo mês, em virtude do crescimento do sistema radicular das plantas. Os volumes aplicados diariamente foram medidos através de mangueira graduada acoplada nos tanques de distribuição.

As irrigações foram realizadas diariamente calculadas com base na evaporação do tanque classe A. Para o cálculo dos volumes de água aplicados foram considerados os diferentes estádios de desenvolvimento da cultura além do fator de cobertura ao longo do ciclo da cultura, sendo a necessidade de irrigação líquida diária (NIL) determinada pela Eq. 1.

$$
\text { NIL Diária }=0,88 \times \mathrm{Kc} \times \text { Epan } \times \mathrm{Cs}
$$

em que:

Kc - coeficiente de cultivo da cultura (tabelado)

Epan - evaporação diária do tanque classe A, mm

Cs - coeficiente de cobertura do solo (tabelado)

A necessidade de irrigação bruta (NIB) diária foi determinada pela Eq. 2.

$$
\text { NIB Diária }=\frac{\text { NIL Diária }}{(1-\mathrm{FL}) \times \mathrm{Ei}}
$$

em que:

Ei - eficiência do sistema de irrigação

FL - fração de lixiviação, estimada pela Eq. 3 .

$$
\mathrm{FL}=\frac{\mathrm{CEa}}{(5 \times \mathrm{CEes}-\mathrm{CEa})}
$$

em que:

CEa - condutividade elétrica da água de irrigação
CEes - condutividade elétrica limite do extrato de saturação do solo, em que o rendimento potencial da cultura ainda é de $100 \%$

A colheita foi iniciada quando as bananas atingiam o calibre de 36 a $38 \mathrm{~mm}$, comumente utilizado para o mercado interno cuja fruta atinge maior desenvolvimento e peso. A colheita do primeiro ciclo foi concluída aos 15 meses após o plantio das mudas, a do segundo 8 meses após a colheita do primeiro e a do terceiro 8 meses após a colheita do segundo, com duração média de 15 meses por ciclo. Os segundo e terceiro ciclos foram iniciados quando houve emissões das inflorescências das plantas do primeiro e segundo ciclos, respectivamente, o que dava uma diferença de idade entre ciclos em torno de 8 meses. A escolha dos rebentos para formação dos segundo e terceiro ciclos recaiu sobre aqueles mais desenvolvidos.

A qualidade da produção da bananeira Nanicão nos ciclos mencionados foi avaliada através de observações das seguintes variáveis: comprimento do fruto médio, diâmetro do fruto médio, ${ }^{\circ}$ Brix e pH da polpa do fruto.

Os efeitos de diferentes tipos e doses de biofertilizante na qualidade da produção da bananeira Nanicão foram avaliados através de métodos normais de análises de variância (Teste $\mathrm{F}$ ) utilizando-se o modelo polinomial enquanto o confronto de médias foi feito pelo teste de Tukey. O programa estatístico SISVAR foi utilizado visando à realização das análises estatísticas.

\section{Resultados e Discussão}

As análises estatísticas revelaram efeitos significativos das doses de biofertilizante os níveis de 0,01 e 0,05 de probabilidade, pelo teste $\mathrm{F}$, sobre o comprimento e o diâmetro do fruto da bananeira Nanicão em 3 ciclos sucessivos, correspondentes às plantas mãe, filha e neta (Tabela 2); no entanto, não afetaram de forma significativa o ${ }^{\circ}$ Brix nem o $\mathrm{pH}$ da polpa do fruto. Por sua vez, os tipos de biofertilizantes não afetaram de forma significativa as referidas variáveis. Para todas as variáveis a interação não apresentou significância estatística.

As equações de regressão ajustadas aos dados experimentais do comprimento do fruto da bananeira Nanicão em três ciclos sucessivos e em relação às doses de biofertilizante, tiveram comportamento quadrático com coeficientes de determinação variando de 0,89 a 0,97 (Figura $1 \mathrm{~A}$ ). Observa-se que o comprimento médio do fruto aumentou com o incremento da dose de biofertilizante até os limites ótimos de 1,10;0,82 e $0,97 \mathrm{~L}_{\text {planta }}{ }^{-1}$ por vez para as plantas dos 1,2 e $3^{\circ}$ ciclos da bananeira Nanicão, respectivamente, que proporcionaram valores máximos de 22,5; 25,9 e 22,7 cm havendo reduções a partir desses limites. Borges et al. (2002) também observaram efeitos positivos da adubação orgânica em bananeiras em que o uso de esterco como fonte de adubo para as plantas promoveu aumento no comprimento de fruto estando de acordo com Damatto Júnior et al. (2011), ao verificarem diminuição no comprimento do fruto da bananeira Prata-Anã com diminuição da quantidade de composto orgânico aplicado ao solo. 
Tabela 2. Resumo das análises de variância do comprimento e diâmetro do fruto, sólidos solúveis totais ( ${ }^{\circ}$ Brix) e $\mathrm{pH}$ da polpa do fruto da bananeira Nanicão, em 3 ciclos sucessivos, correspondentes às plantas mãe, filha e neta, respectivamente

\begin{tabular}{|c|c|c|c|c|c|}
\hline \multirow{3}{*}{ Fontes de variação } & \multirow{3}{*}{ GL } & \multicolumn{4}{|c|}{ Quadrados médios } \\
\hline & & Comp. & Diâmetro & ${ }^{\circ}$ Brix & $\mathrm{pH}$ \\
\hline & & \multicolumn{2}{|c|}{ do fruto médio } & \multicolumn{2}{|c|}{ da polpa do fruto } \\
\hline & \multicolumn{5}{|c|}{ Ciclo 1 - Planta mãe } \\
\hline Doses de biofertilizante (D) & 4 & 13,30 ** & $17,76^{\star}$ & 10,39 & 0,23 \\
\hline Regressão linear & 1 & $32,40 * *$ & 8,55 & 36,10 & 0,02 \\
\hline Regressão quadrática & 1 & $19,44^{*}$ & $55,00 * \star$ & 2,16 & 0,07 \\
\hline Regressão cúbica & 1 & 1,22 & 2,75 & 3,02 & 0,75 \\
\hline Desvio da regressão & 1 & 0,12 & 4,75 & 0,28 & 0,07 \\
\hline Tipos de biofertilizante (T) & 3 & 5,51 & 6,23 & 11,34 & 0,40 \\
\hline Interação D x T & 12 & 3,53 & 5,57 & 8,66 & 0,26 \\
\hline Resíduo & 60 & 3,08 & 5,85 & 8,83 & 0,44 \\
\hline \multirow[t]{2}{*}{ Coeficiente de variação (\%) } & & 8,06 & 5,13 & 18,20 & 13,43 \\
\hline & \multicolumn{5}{|c|}{ Ciclo 2 - Planta filha } \\
\hline Doses de biofertilizante (D) & 4 & $25,04^{\star \star}$ & $114,45^{\star \star}$ & 11,98 & 0,43 \\
\hline Regressão linear & 1 & 0,50 & 1,22 & 40,00 & 0,40 \\
\hline Regressão quadrática & 1 & $96,46^{\star \star}$ & $391,14^{\star *}$ & 1,14 & 0,64 \\
\hline Regressão cúbica & 1 & 0,40 & $65,02^{*}$ & 3,90 & 0,50 \\
\hline Desvio da regressão & 1 & 2,80 & 0,43 & 2,90 & 0,20 \\
\hline Tipos de biofertilizante (T) & 3 & 1,24 & 15,61 & 12,14 & 0,27 \\
\hline Interação D x T & 12 & 3,40 & 10,43 & 8,31 & 0,11 \\
\hline Resíduo & 60 & 3,39 & 9,13 & 9,23 & 0,33 \\
\hline \multirow[t]{2}{*}{ Coeficiente de variação (\%) } & & 7,48 & 6,11 & 17,97 & 11,20 \\
\hline & \multicolumn{5}{|c|}{ Ciclo 3 - Planta neta } \\
\hline Doses de biofertilizante (D) & 4 & $33,54^{\star \star}$ & $71,31 * *$ & 10,73 & 0,80 \\
\hline Regressão linear & 1 & $40,00 * *$ & $162,00 * *$ & 31,50 & 0,50 \\
\hline Regressão quadrática & 1 & $80,16^{\star \star}$ & $107,25^{\star}$ & 10,71 & 1,96 \\
\hline Regressão cúbica & 1 & 12,65 & 0,90 & 0,30 & 0,02 \\
\hline Desvio da regressão & 1 & 1,35 & 15,08 & 0,39 & 0,70 \\
\hline Tipos de biofertilizante (T) & 3 & 2,36 & 4,21 & 12,24 & 0,24 \\
\hline Interação D x T & 12 & 5,21 & 21,00 & 9,71 & 0,22 \\
\hline Resíduo & 60 & 4,56 & 19,79 & 8,25 & 0,32 \\
\hline Coeficiente de variação (\%) & & 9,96 & 10,01 & 17,17 & 10,85 \\
\hline
\end{tabular}

É provável que os aumentos verificados até as doses ótimas de biofertilizante nos ciclos mencionados tenham sido devidos à melhoria das características físicas, químicas e biológicas do solo com o decorrer do tempo (Damatto Júnior et al., 2009). O potencial de fertilidade do solo é aumentado pelo efeito da quelação imediata do complexo de moléculas orgânicas dos biofertilizantes possibilitando maior solubilização de nutrientes e mobilização para os sistemas das plantas resultando em plantas nutricialmente mais equilibradas (Dosani et al., 1999). Acima de cada limite ótimo o comprimento do fruto médio da bananeira Nanicão foi reduzido (Figura 1A) podendo estar associado ao aumento da população de microrganismos em função do aumento das doses de biofertilizantes ocorrendo, em consequência, aumento acentuado do consumo de nutrientes com redução da sua disponibilidade para as plantas (Malavolta et al., 1997), bem como à toxicidade de plantas provocada pelo excesso de nutrientes fornecidos nas adubações (Huett, 1989).

Observa-se, também, na Figura 1A, que o comprimento do fruto médio do segundo ciclo foi superior ao do primeiro e do terceiro sendo que, por sua vez, os primeiro e terceiro ciclos apresentaram valores praticamente semelhantes. Nas doses ótimas de biofertilizante a planta filha $\left(2^{\circ}\right.$ ciclo) superou as plantas mãe
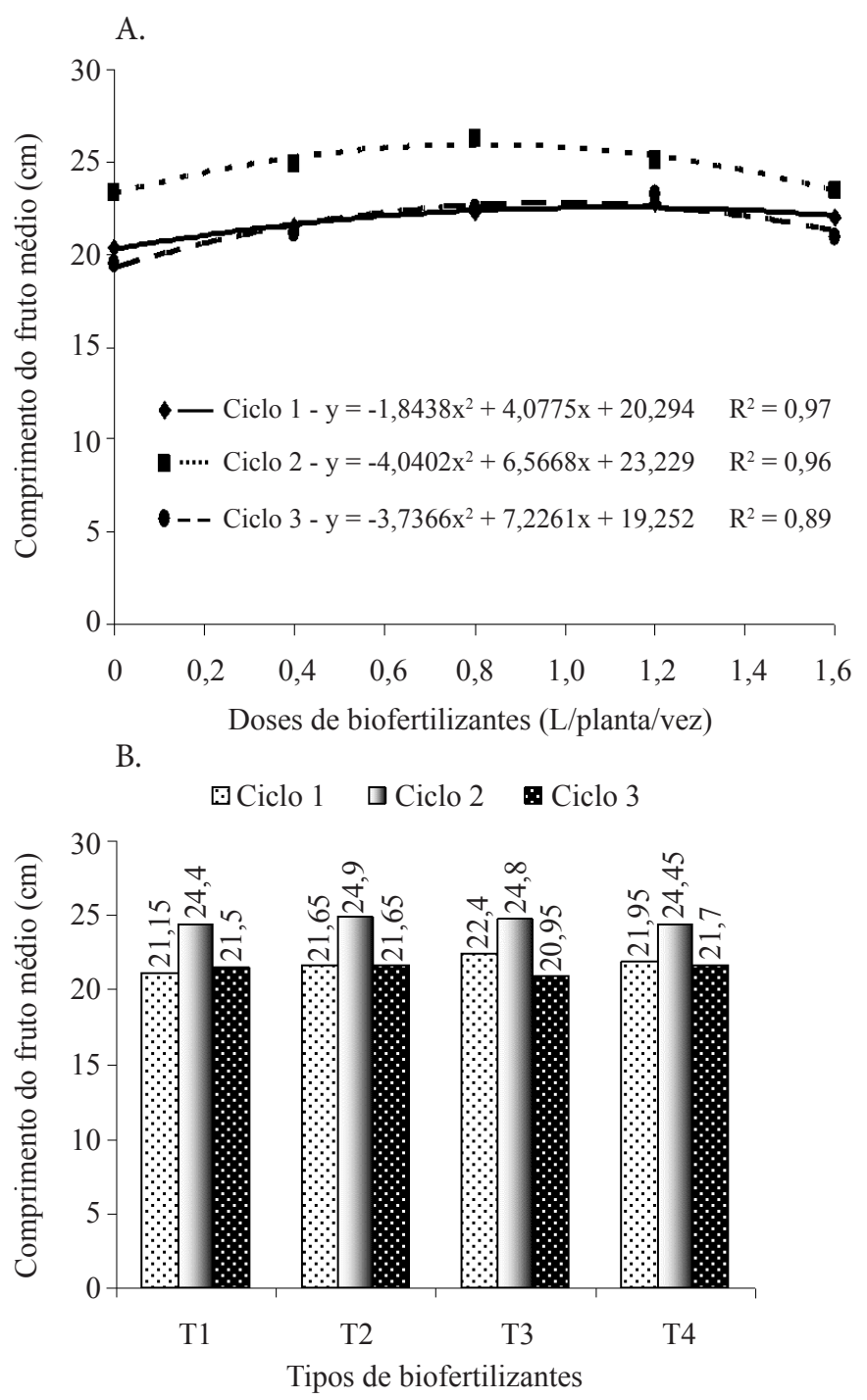

$\mathrm{B}_{1}$ - não enriquecidos à base de esterco, $\mathrm{B}_{2}$ - enriquecidos à base de esterco, $\mathrm{B}_{3}$ - não enriquecidos à base de soro $\mathrm{e}_{4}$ - enriquecidos à base de soro

Figura 1. Comprimento do fruto médio da bananeira Nanicão $\left(1^{\circ}, 2^{\circ}\right.$ e $3^{\circ}$ ciclos) em função de doses (A) e tipos (B) de biofertilizante

( $1^{\circ}$ ciclo) e neta ( $3^{\circ}$ ciclo) em 13,1 e $12,4 \%$, respectivamente. Damatto Júnior et al. (2011) observaram, trabalhando com a bananeira Prata-Anã não adubada, maior comprimento do fruto médio no primeiro ciclo, valor intermediário no segundo e menor valor no terceiro; no entanto, no quarto ciclo, com a adoção da adubação com composto orgânico, o valor de comprimento do fruto médio superou os valores obtidos nos primeiro, segundo e terceiro ciclos, em 5,2; 9,1 e 14,3\%, respectivamente.

Com relação aos efeitos dos tipos de biofertilizante (Figura 1B) os valores de comprimento do fruto médio não apresentaram diferenças significativas entre si dentro de cada ciclo da bananeira variando de 21,1 a $22,4 \mathrm{~cm}$ no primeiro ciclo, de 24,4 a $24,9 \mathrm{~cm}$ no segundo e de 21,0 a $21,7 \mathrm{~cm}$ no terceiro, chegando a valores médios de $21,8 \mathrm{~cm}$ no primeiro ciclo, de $24,6 \mathrm{~cm}$ no segundo e de $21,4 \mathrm{~cm}$ no terceiro havendo, portanto, superioridade do segundo ciclo sobre os primeiro e terceiro de 11,4 e $11,8 \%$, respectivamente, tal como do primeiro ciclo em relação ao terceiro, de $3,4 \%$. 
A superioridade do comprimento do fruto médio do segundo ciclo em relação à do primeiro, pode ser explicada pela melhoria crescente das características do solo com o passar do tempo devido à aplicação de biofertilizantes, como já foi frisado. Damatto Júnior et al. (2011) verificaram elevação significativa da massa média do cacho da bananeira Prata-Anã do primeiro para o segundo ciclo em função da adubação aplicada no primeiro ano, que serviu como fonte de reserva de nutrientes para as plantas da família.

Outra vertente que pode explicar o fato é defendida por Silva et al. (2003) ao afirmar que a produção de banana também é influenciada por fatores internos da planta, como os genéticos de acordo, portanto, com Silva et al. (2002), que defendem a tese de que o primeiro ciclo não é adequado para analisar a massa do cacho para a maioria das cultivares de banana de vez que tal característica pode aumentar do primeiro para o segundo ciclo.

A superioridade do segundo ciclo em relação ao terceiro e a igualdade do primeiro com o terceiro podem ser atribuídas provavelmente ao fato do ciclo da planta neta ter sido transcorrido mais no período de verão tendo havido necessidade de um período maior de irrigação com também maior acúmulo de sais no solo o que, possivelmente, contribuiu para uma elevação maior da salinidade e, consequentemente, para a redução do comprimento do fruto médio no terceiro ciclo da bananeira.

As equações de regressão ajustadas aos dados experimentais do diâmetro do fruto médio da bananeira Nanicão, em relação às doses de biofertilizante também tiveram comportamento quadrático com coeficientes de determinação variando de 0,86 a 0,94 (Figura 2A). Observa-se que o diâmetro do fruto médio aumentou com o incremento da dose de biofertilizante até os limites ótimos de 0,71; 0,79 e 1,09 $\mathrm{L}_{\text {planta- }}{ }^{-1}$ por vez, para as plantas dos $1^{\circ}, 2^{\circ}$ e $3^{\circ}$ ciclos, respectivamente, que proporcionaram valores máximos de 48,2; 52,1 e 46,2 mm, havendo reduções a partir desses limites. Damatto Júnior et al. (2011) verificaram tendência similar de diminuição do diâmetro do fruto da bananeira Prata-Anã com a supressão da quantidade de composto orgânico aplicado ao solo. Os aumentos do diâmetro do fruto médio verificados até as doses ótimas de biofertilizante e as reduções acima dos limites ótimos podem ser explicados pelas mesmas razões citadas para o comprimento do fruto médio.

Observa-se também, na Figura $2 \mathrm{~A}$, que o diâmetro do fruto médio do segundo ciclo foi superior aos do primeiro e terceiro ciclos. Os diâmetros do fruto médio das plantas do primeiro ciclo foram superiores aos das plantas do terceiro ciclo até a dose de 1,2 L planta-1 ${ }^{-1}$ or vez igualando-se a partir daí. Nas doses ótimas a planta filha $\left(2^{\circ}\right.$ ciclo $)$ superou as plantas mãe $\left(1^{\circ}\right.$ ciclo $)$ e neta ( $3^{\circ}$ ciclo) em $7,5 \%$ e $11,3 \%$, respectivamente ocorrendo, também, superioridade da mãe em relação à neta, de 4,1\%. Damatto Júnior et al. (2011) verificaram maior diâmetro do fruto médio no primeiro ciclo, valor intermediário no segundo e menor valor no terceiro ciclo da bananeira Prata-anã não adubada; no entanto, no quarto ciclo, com a adoção da adubação com composto orgânico, o valor do diâmetro do fruto médio superou os valores obtidos nos segundo e terceiro ciclos em
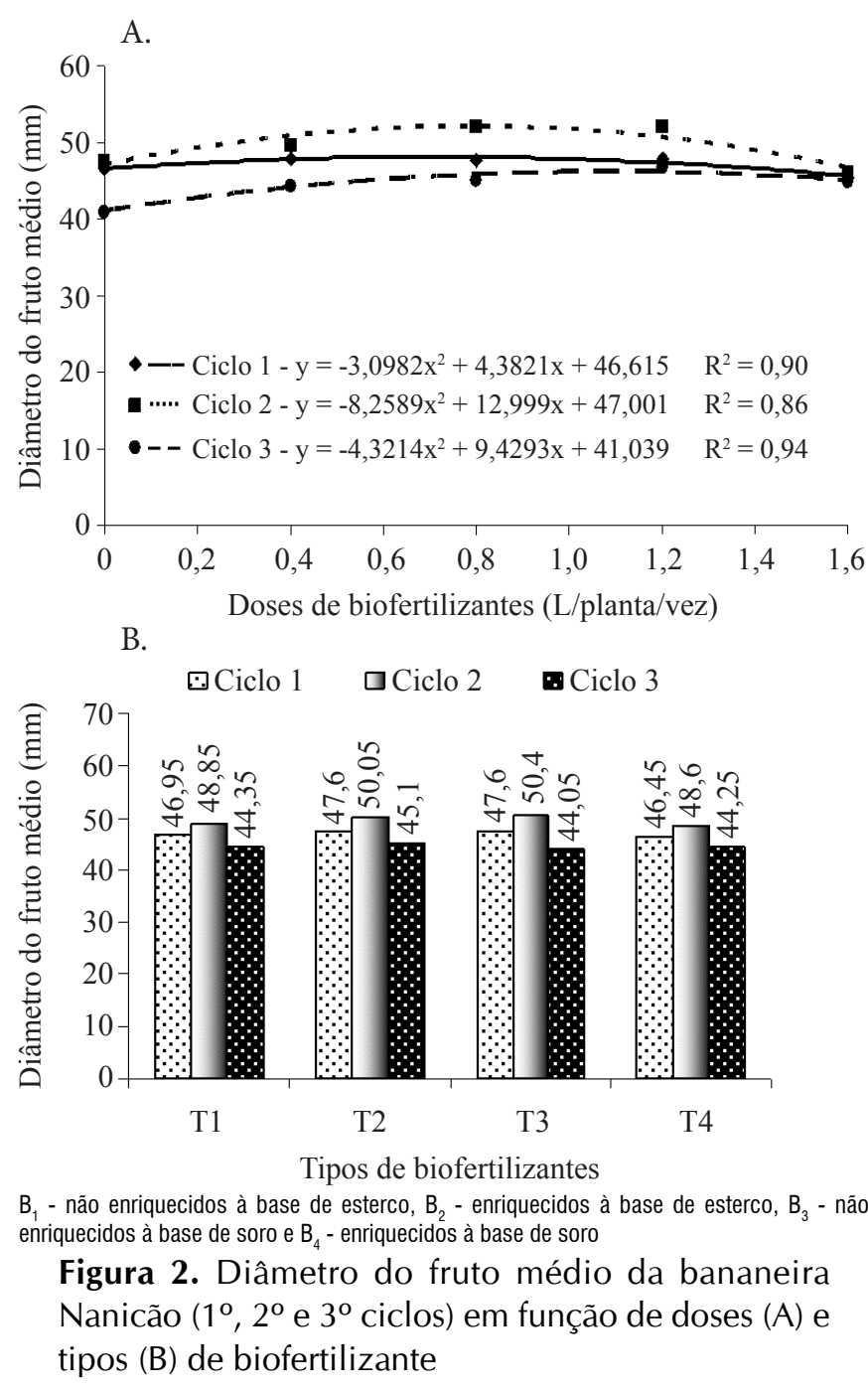

3,8 e $8,6 \%$, respectivamente, embora tenha sido superado pelo primeiro ciclo em $6,6 \%$.

Com relação aos efeitos dos tipos de biofertilizante (Figura $2 \mathrm{~B})$, observa-se que os valores de diâmetro do fruto médio não apresentaram diferenças significativas entre si em cada ciclo da bananeira, variando de 46,4 a $47,6 \mathrm{~mm}$ no primeiro ciclo, de 48,6 a $50,4 \mathrm{~mm}$ no segundo e de 44,0 a $45,1 \mathrm{~mm}$ no terceiro chegando a valores médios de $47,2 \mathrm{~mm}$ no primeiro ciclo, de $49,5 \mathrm{~mm}$ no segundo e de $44,4 \mathrm{~mm}$ no terceiro havendo, portanto, superioridade do segundo ciclo sobre o primeiro e terceiro de 4,6 e $10,3 \%$, respectivamente tal como do primeiro ciclo em relação ao terceiro de 5,9\%.

A superioridade do segundo ciclo em relação ao primeiro pode ser explicada pela melhoria das características do solo respaldada nas teorias de Damatto Júnior et al. (2009) e Silva et al. (2003). A superioridade do segundo ciclo em relação ao terceiro pode ser explicada pela elevação da salinidade do solo por ocasião do ciclo da planta neta, fato já mencionado para o comprimento do fruto médio.

Os efeitos não significativos das doses de biofertilizante sobre os valores dos sólidos solúveis totais ( ${ }^{\circ} \mathrm{Brix}$ ) da polpa do fruto médio da bananeira Nanicão podem ser observados na Figura 3 , em que os valores não apresentaram diferenças significativas 
entre si dentro de cada ciclo da bananeira variando de 15,31 a $17,25^{\circ}$ Brix no primeiro ciclo, de 15,87 a 18,0 no segundo e de 15,43 a 17,56 no terceiro chegando a valores médios de 16,33 ${ }^{\circ}$ Brix no primeiro ciclo, de 16,91 no segundo e de 16,73 no terceiro constatando-se, portanto, superioridade do segundo ciclo sobre os primeiro e terceiro de 3,4 e 1,1\%, respectivamente, assim como do terceiro ciclo em relação ao primeiro de $2,4 \%$.

Com relação aos efeitos dos tipos de biofertilizante (Figura $3 \mathrm{~B})$, os valores de ${ }^{\circ}$ Brix da polpa do fruto médio também não apresentaram diferenças significativas entre si dentro de cada ciclo da bananeira variando de 15,85 a $17,45^{\circ}$ Brix no primeiro ciclo, de 16,2 a 18,0 no segundo e de 16,1 a 17,85 no terceiro ciclo, chegando a valores médios de $16,33^{\circ}$ Brix no primeiro ciclo, de 16,91 no segundo e de 16,73 no terceiro, apresentando os mesmos percentuais de superioridade do segundo ciclo sobre os primeiro e terceiro, bem como do terceiro ciclo sobre o primeiro, citados para efeitos de doses de biofertilizante. Ferreira et al. (2006) não observaram, estudando a qualidade do tomate em diferentes doses de nitrogênio e adubação orgânica, alterações nos sólidos solúveis totais dos frutos.

Nascimento Júnior et al. (2008) afirmam que os valores encontrados na literatura para ${ }^{\circ}$ Brix em banana oscilam entre 19,72 a 22,36 para o fruto maduro. Barroso et al. (2012) encontraram valores de ${ }^{\circ} \mathrm{Brix}$ dos frutos da bananeira variando de 18,88 a 19,30 em diferentes lâminas de água de irrigação, com valor médio de 19,11.
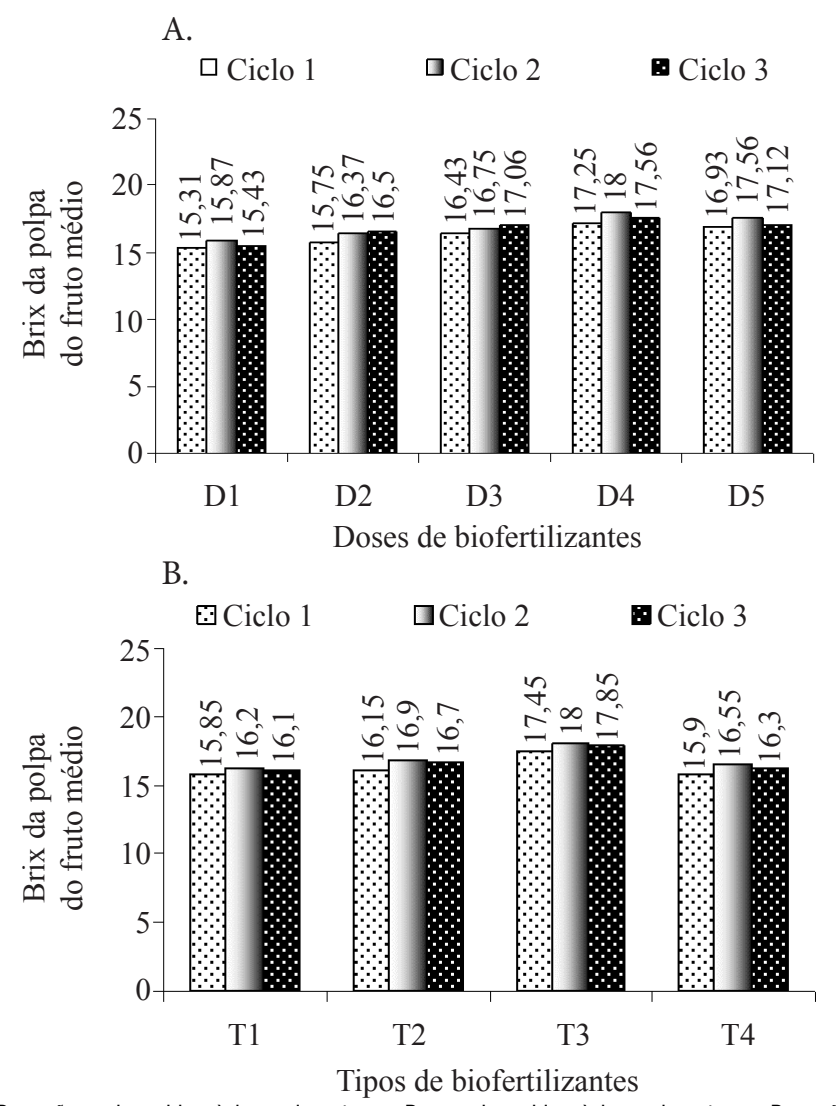

$B_{1}$ - não enriquecidos à base de esterco, $B_{2}$ - enriquecidos à base de esterco, $B_{3}$ - não enriquecidos à base de soro e $\mathrm{B}_{4}$ - enriquecidos à base de soro

Figura 3. Sólidos solúveis totais ( ${ }^{\circ}$ Brix) da polpa da bananeira Nanicão $\left(1^{\circ}, 2^{\circ}\right.$ e $3^{\circ}$ ciclos) em função de doses (A) e tipos (B) de biofertilizante
Os efeitos não significativos das doses de biofertilizante sobre o $\mathrm{pH}$ da polpa do fruto médio maduro da bananeira Nanicão podem ser observados na Figura 4A. Observa-se que os valores não apresentaram diferenças significativas entre si dentro de cada ciclo da bananeira variando de 4,81 a 5,0 no primeiro ciclo, de 4,93 a 5,37 no segundo e de 5,0 a 5,62 no terceiro, chegando a valores médios de 4,95 no primeiro ciclo de 5,18 no segundo e de 5,29 no terceiro havendo, portanto, superioridade do terceiro ciclo sobre os primeiro e segundo de 6,4 e $2,1 \%$, respectivamente, e do segundo ciclo em relação ao primeiro, de $4,4 \%$.

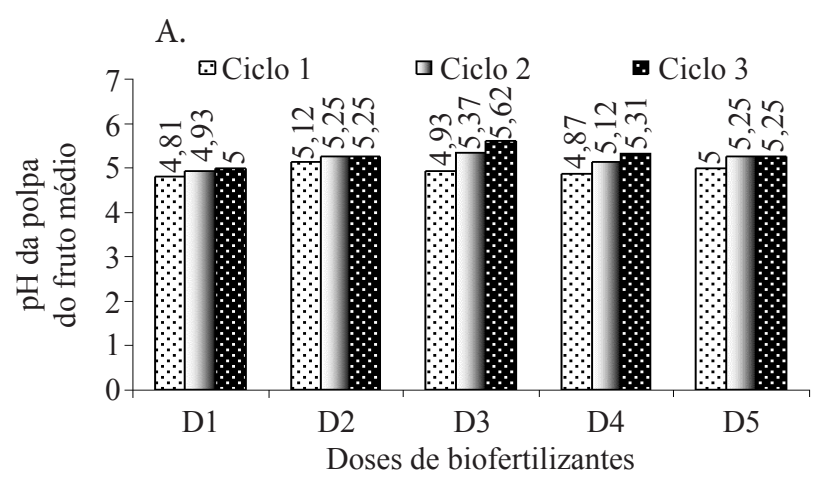

B.

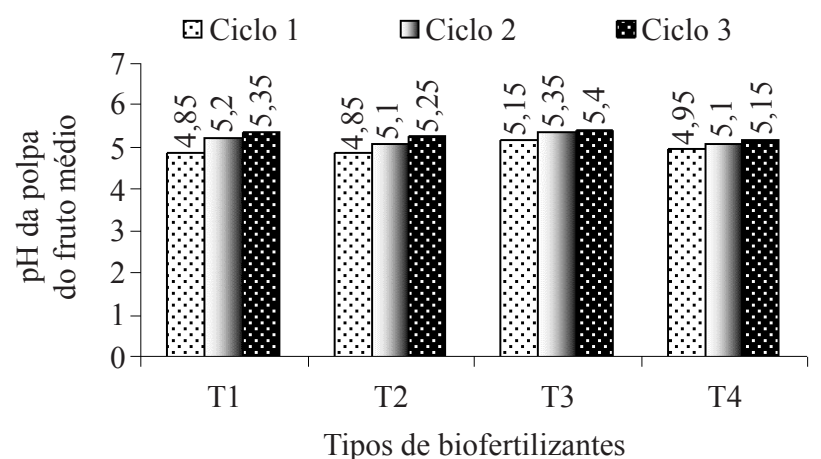

$\mathrm{B}_{1}$ - não enriquecidos à base de esterco, $\mathrm{B}_{2}$ - enriquecidos à base de esterco, $\mathrm{B}_{3}$ - não enriquecidos à base de soro $\mathrm{e}_{4}$ - enriquecidos à base de soro

Figura 4. Potencial hidrogeniônico $(\mathrm{pH})$ da polpa da bananeira Nanicão $\left(1^{\circ}, 2^{\circ}\right.$ e $3^{\circ}$ ciclos) em função de doses (A) e tipos (B) de biofertilizante

Quanto aos efeitos dos tipos de biofertilizante (Figura 4B) observa-se que os valores de $\mathrm{pH}$ da polpa do fruto médio maduro também não apresentaram diferenças significativas entre si dentro de cada ciclo da bananeira variando de 4,85 a 5,15 no primeiro, de 5,1 a 5,35 no segundo e de 5,15 a 5,4 no terceiro ciclo, apresentando os mesmos percentuais de superioridade do terceiro ciclo sobre os primeiro e segundo, bem como do segundo sobre o primeiro, citados para os efeitos de dosagens de biofertilizante. As variações encontradas neste trabalho se mantiveram abaixo da faixa defendida por Ballestero (1992), que é de 4,2 a 4,8 .

\section{Conclusões}

1. Os tipos de biofertilizante não afetaram de forma significativa as variáveis de qualidade da bananeira Nanicão, nos três ciclos estudados. 
2. O comprimento e o diâmetro do fruto médio aumentaram com o incremento da dosagem de biofertilizante até limites ótimos, proporcionando valores máximos dessas variáveis nos três ciclos estudados, sendo que essas mesmas variáveis apresentaram um decréscimo, quando foram submetidas a doses acima dos limites ótimos.

3. O comprimento do fruto médio das plantas do segundo ciclo foi superior aos das plantas do primeiro e do terceiro ciclos, em 13,1 e 12,4\%, respectivamente, bem como o diâmetro do fruto que foi superior aos das plantas do primeiro e do terceiro ciclos em 7,5 e 11,3\%, respectivamente.

4. Os valores de graus Brix e de $\mathrm{pH}$ da polpa do fruto médio não foram influenciados pelos biofertilizantes nos três ciclos de cultivo.

\section{Literatura Citada}

Agrianual. Anuário da Agricultura Brasileira. 14.ed. São Paulo: FNP Consultoria e Comércio, 2009. 496p.

Ballestero, M. S. Banano - Cultivo y comercialización. 2.ed. San José: Litografia e Imprensa LIL, 1992. 674p.

Barroso, A. de A. F.; Viana, T. V. de A.; Marinho, A. B.; Santos, L. M. de L.; Barroso, C. R. de O.; Fiho, R. R. G. Qualidade pós-colheita dos frutos da bananeira, sob diferentes lâminas de irrigação na chapada do Apodi - Ceará. Revista Brasileira de Agricultura Irrigada, v.6, p.81-88, 2012.

Borges, A. L.; Silva, T. O. da; Caldas, R. C.; Almeida, I. E. de A. Adubação nitrogenada para bananeira terra (Musa sp. AAB, subgrupo Terra). Revista Brasileira de Fruticultura, v.24, p.189-193, 2002.

Damatto Júnior, E. R.; Nomura, E. S.; Fuzitani, E. J.; Saes, L. A. Experiências com o uso de adubação orgânica na cultura da banana. In: Godoy, L. J. G.; Gomes, J. M. Tópicos sobre nutrição e adubação da cultura da banana. Botucatu: FEPAF/ UNESP, 2009. p.94-120.

Damatto Júnior, E. R.; Villas Bôas, R. L.; Leonel, S.; Fernandes, D. M. Alterações em propriedades de solo adubado com doses de composto orgânico sob cultivo de bananeira. Revista Brasileira de Fruticultura, v.28, p.546-549, 2006.

Damatto Júnior, E. R.; Villas-Bôas, R. L.; Leonel, S.; Nomura, E. S.; Fuzitani, E. Crescimento e produção da bananeira Prata-Anã adubada com composto orgânico durante cinco safras. Revista Brasileira de Fruticultura, v. especial, p.713721, 2011.

Dosani, A. A. K.; Talashilkar, S. C.; Mehta, V. B. Effect of organic mamure applied in combination with fertilizers on the yield, quality and nutrient of groundnut. Journal of the. Indian Society of Soil Science, v.47, p.166-169, 1999.

Ferreira, M. M. M.; Ferreira, G. B.; Fontes, P. C. R.; Dantas, J. P. Qualidade do tomate em função de doses de nitrogênio e da adubação orgânica em duas estações. Horticultura Brasileira, v.24, p.141-145, 2006.
Gonçalves, V. D.; Nietsche, S.; Pereira, M. C. T.; Silva, S. O.; Santos, T. M. dos; Oliveira, J. R.; Franco, L. R. L.; Ruggiero, C. Avaliação das cultivares de bananeira Prata-Anã, Trap Maeo e Caipira em diferentes sistemas de plantio no Norte de Minas Gerais. Revista Brasileira de Fruticultura, v.30, p.371-376, 2008.

Guerra, J. G. M.; Nidiaye, A.; Assis, R. L. de; Espindola, J. A. A. Uso de plantas de cobertura na valorização de processos ecológicos em sistemas orgânicos de produção na região serrana fluminense. Revista Agricultura, v.4, p.1-28, 2007.

Huett, D. O. Effect of nitrogen on the yield and quality of vegetables. Acta Horticulturae, v.247, p.205-209, 1989.

Malavolta, E.; Vitti, G. C.; Oliveira, S. A. Avaliação do estado nutricional das plantas: princípios e aplicações. 2.ed. Piracicaba: Potafos, 1997. 201p.

Nascimento Júnior, B. B. do; Ozorio, L. P.; Rezende, C. M.; Soares, A. G.; Fonseca, M. J. O. Diferenças entre bananas de cultivares Prata e Nanicão ao longo do amadurecimento: características físico-químicas e compostos voláteis. Ciência e Tecnologia de Alimentos, v.28, p.649-658, 2008.

Oliveira, A. P.; Souza, C. M. Influência da cobertura morta na umidade, incidência de plantas daninhas e de broca-dorizoma (Cosmopolites sordidus) em um pomar de bananeiras (Musa spp.). Revista Brasileira de Fruticultura, v.25, p.345347, 2003.

Santos, A. C. V.; Akiba, F. Biofertilizante líquido: Uso correto na agricultura alternativa. Seropédica: UFRRJ, Imprensa Universitária, 1996. 35p.

Santos J. G. R. dos; Santos, E. C. X. R dos. Adubos orgânicos e defensivos naturais. In: Santos J. G. R. dos; Santos, E. C. $\mathrm{X}$. R dos. Agricultura orgânica: Teoria e prática. Campina Grande: EDUEP, 2008. Cap. 3, p.57-84.

Sarudi, C.; Szakaly, Z.; Mathe, A.; Szente, V. The of organic agriculture in rural development. Agriculture Conspectus Scientificus Polijopriredna Znanstvena, v.68, p.197-202, 2003.

Silva, J. T. A. da; Borges, A. L.; Carvalho, J. G.; Damasceno, J. E. A. adubação com potássio em três ciclos de produção da bananeira cv. Prata Anã. Revista Brasileira de Fruticultura, v.25, p.179-184, 2003.

Silva, S. O.; Flores, J. C. O.; Lima Neto, F. P. Avaliação de cultivares e híbridos de bananeira em quatro ciclos de produção. Pesquisa Agropecuária Brasileira, v.37, p.15671574, 2002.

Tracth, R.; Bettiol, W. Efeito de biofertilizantes sobre o crescimento micelial e a germinação de esporos de alguns fungos fitopatogênicos. Pesquisa Agropecuária Brasileira, v.32, p.1131-1139, 1997.

Wong, M. T. F.; Akeampong, E.; Nortcliff, S.; Rao, M. R.; Swife, R. S. Initial responses of maize and beans to decreased concentrations of monomeric inorganic aluminium with application of manure or tree prunings to an oxisol in Burundi. Plant and Soil, v.171, p.275-82, 1995. 